\title{
Behind the faces: Alzheimer's disease and emotional blindness
}

\author{
Por trás das faces: doença de Alzheimer e cegueira emocional \\ Jerusa Smid ${ }^{1,2}$, Tarso Adoni1,3
}

1 Universidade de São Paulo, Faculdade de Medicina, Departamento de Neurologia, Sao Paulo SP, Brazil;

${ }^{2}$ Instituto de Infectologia Emílio Ribas, Divisão de Neurologia, Sao Paulo SP, Brazil;

${ }^{3}$ Hospital Sírio-Libanês, Divisão de Neurologia, Sao Paulo SP, Brazil.

Correspondence: Jerusa Smid; Rua Itapeva, 538 - conj 132; 01332-000 São Paulo SP, Brasil; E-mail:jsmid77@hotmail.com

Conflict of interest:

There is no conflict of interest to declare.

Received 31 March 2015

Accepted 07 April 2015

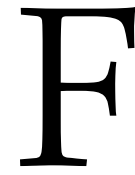

ace emotional recognition (FER), empathy, emotional inference, decision-making, theory of mind are some of the various aspects of social cognition ${ }^{1}$. FER is involved in other aspects of social cognition and its impairment would interfere in the performance of other components of the social network. The six emotions commonly studied are: happiness, surprise, anger, disgust, fear and sadness.

The expression of emotions and their recognition by others was already addressed by the naturalist Charles Darwin in his famous book "The Expression of the Emotions in Man and Animals"2. Darwin showed that the expression of emotions is evolutionarily conserved among species and that this fact should have an adaptive and survival implication. The American psychologist Paul Ekman, not without controversy, devoted to the systematic and exhaustive study of facial expressions of the different emotions in the last decades of the twentieth century ${ }^{3}$.

However, perhaps the most important aspect in the understanding of expression of emotions was brought to light recently by Rizzolatti team with the discovery of so-called mirror neurons ${ }^{4}$. According to neuroscientist Vilayanur Ramachandran, "mirror neurons will do for psychology what DNA did for biology"5. He says that the appearance of mirror neurons, first detected in the ventral premotor area of macaque monkeys, led to the discovery of expressed emotion ("read mind"), anticipating the most appropriate response for social interaction and the success of community living. Ultimately, mirror neurons would be the anatomical substrate for empathy. Therefore, it is easy to understand that the loss of this essential skill for our entire social and emotional performance can be quite problematic.

The study of social cognition runs parallel to the study of traditional cognitive tasks in the field of dementia. It is possible that the different performance on tests that evaluate social cognition may be of clinical utility to differentiate the causes of dementia, especially in the initial phase of the main dementia of degenerative etiology ${ }^{6,7.8}$. The distinction between the two main forms of primary dementia in pre-senile age, frontotemporal dementia (FTD) and Alzheimer's disease $(\mathrm{AD})$, can be difficult in clinical practice. The impairment of episodic memory, which is considered a hallmark in AD, may occur in FTD, even in the beginning of the disease ${ }^{9}$. In contrast, social cognition is impaired markedly in the behavioral variant of FTD (bvFTD), progressive disease characterized by changes in behavior and personality, with decreased empathy, disinhibition, inappropriate behavior, difficulty in social interaction, loss of insight, hyperorality and impulsivity. Usually, behavioral changes precede the traditional cognitive deficits.

Few studies address the involvement of social cognition in patients with $\mathrm{AD}$. The results are contradictory and can be explained by the small number of patients and different forms of assessment. Some studies of patients with amnestic mild cognitive impairment point to the maintenance of integrity in the $\mathrm{FER}^{10}$ or mild difficulty especially in the detection of negative emotions (anger, fear and sadness) $)^{11,12}$. However, these same studies indicate a greater impairment in FER and mild difficulty in socioemotional battery in patients diagnosed with mild $\mathrm{AD}^{6,13}$. A comparative study of bvFTD, $\mathrm{AD}$ and semantic dementia showed that, although there is impairment in performance tests to face emotion processing in all patients in initial stage, different underlying cognitive substrates were proposed ${ }^{14}$.

In this issue of Arquivos de Neuropsiquiatria, the paper published by Torres et al. ${ }^{15}$, in the wake of previous study in patients with $\mathrm{FTD}$, vascular dementia and even $\mathrm{AD}^{16}$, brings relevant information on social cognition in mild $\mathrm{AD}$ patients. The authors evaluated the performance 
on face recognition task longitudinally in 30 mild $\mathrm{AD}$ patients. Patients with $\mathrm{AD}$ got worse six months later in the task that measures the ability of inferring the emotional content of a scene. Tasks of simple facial recognition were normal at first visit and remained stable. The findings in this study of Torres et al. correlated with global cognitive decline. Similar findings have been previously reported, indicating that in the beginning of $\mathrm{AD}$, simple face recognition processing is intact, in contrast with other types of dementia ${ }^{7}$. Another longitudinal study that followed patients for 3 years also indicated a decline in performance of the FER in patients over time ${ }^{17}$.

Although bringing a valuable contribution, some limitations of this study must be pointed. The limited cognitive evaluation with mini-mental state examination does not allow us to exclude certain difficulties in specific cognitive domains to be the actual source of the poor performance in the
FER. Cognitive decline observed between evaluations would interfere in the performance of many tests, not only in FER. Enlarging the sample and adding a control group would improve the power of the results presented.

The capacity to interpret facial emotions is part of the daily lives of individuals who interact socially. It is speculated that the loss of this ability may be responsible, in part, by many behavioral changes in dementia. Behavioral symptoms are a source of stress and burden on caregivers, often more than the actual cognitive symptoms. The understanding and diagnosis of inability of the FER may auxiliary in the early management of behavioral symptoms, in order to improve the quality of life of patients and appropriate interventions. For this reason, the work published here can contribute to a better understanding of the fascinating field of facial recognition disorders.

\section{References}

1. Ibañez A, Manes F. Contextual social cognition and the behavioral variant of frontotemporal dementia. Neurology. 2012;78(17):1354-62. http://dx.doi.org/10.1212/WNL.0b013e3182518375

2. Darwin C. The expression of the emotions in man and animals. London: John Murray, 1872.

3. Ekman P. Emotions revealed: recognizing faces and feelings to improve communication and emotional life. 2nd ed. New York: Owl Books; 2007.

4. Pellegrino G, Fadiga L, Fogassi L, Gallese V, Rizzolatti G. Understanding motor events: a neurophysiological study. Exp Brain Res. 1992;91(1):176-80. http://dx.doi.org/10.1007/BF00230027

5. Ramachandran VS. The tell-tale brain: a neuroscientist's quest for what makes us human. New York: W. W. Norton; 2011.

6. Narme P, Mouras H, Roussel M, Devendeville A, Godefroy O. Assessment of socioemotional processes facilitates the distinction between frontotemporal lobar degeneration and Alzheimer's disease. J Clin Exp Neuropsychol. 2013;35(7):728-44. http://dx.doi.org/10.1080/13803395.2013.823911

7. Kumfor F, Sapey-Triomphe LA, Leyton CE, Burrell JR, Hodges JR, Piguet O. Degradation of emotion processing ability in corticobasal syndrome and Alzheimer's disease. Brain. 2014;137(11):3061-72. http://dx.doi.org/10.1093/brain/awu246

8. Kumfor F, Irish M, Leyton C, Miller L, Lah S, Devenney E et al. Tracking the progression of social cognition in neurodegenerative disorders. J Neurol Neurosurg Psychiatry. 2014;85(10):1076-83. http://dx.doi.org/10.1136/jnnp-2013-307098

9. Hornberger M, Piguet O. Episodic memory in frontotemporal dementia: a critical review. Brain. 2012;135(3):678-92. http://dx.doi.org/10.1093/brain/aws011

10. Bediou B, Brunelin J, Amato T, Fecteau S, Saoud M, Hénaff MA et al. A comparison of facial emotion processing in neurological and psychiatric conditions. Front Psychol. 2012;3:98. http://dx.doi.org/10.3389/fpsyg.2012.00098

11. Spoletini I, Marra C, Di lulio F, Gianni W, Sancesario G, Giubilei F et al. Facial emotion recognition deficit in amnestic mild cognitive impairment and Alzheimer disease. Am J Geriatr Psychiatry. 2008;16(5):389-98. http://dx.doi.org/10.1097/JGP.0b013e318165dbce

12. McCade D, Savage G, Naismith SL. Review of emotion recognition in mild cognitive impairment. Dement Geriatr Cogn Disord. 2011;32(4):257-66. http://dx.doi.org/10.1159/000335009

13. Maki Y, Yoshida H, Yamaguchi T, Yamaguchi H. Relative preservation of the recognition of positive facial expression "happiness" in Alzheimer disease. Int Psychogeriatr. 2013;25(1):105-10. http://dx.doi.org/10.1017/S1041610212001482

14. Miller LA, Hsieh S, Lah S, Savage S, Hodges JR, Piguet O. One size does not fit all: face emotion processing impairments in semantic dementia, behavioural-variant frontotemporal dementia and Alzheimer's disease are mediated by distinct cognitive deficits. Behav Neurol. 2012;25(1):53-60. http://dx.doi.org/10.1155/2012/683052

15. Torres B, Santos RL, Sousa MFB, Simões Neto JP, Nogueira MML, Belfort TT, Dias R, Dourado MCN. Facial expression recognition in Alzheimer's disease: a longitudinal study. Arquivos de Neuro-Psiquiatria 2015;73(5):383-89. http://dx.doi.org/10.1590/0004-282X20150009

16. Shimokawa A, Yatomi N, Anamizu S, Ashikari I, Kohno M, Maki Y et al. Comprehension of emotions: comparison between Alzheimer type and vascular type dementias. Dement Geriatr Cogn Disord. 2000;11(5):268-74. http://dx.doi.org/10.1159/000017249

17. Lavenu I, Pasquier F. Perception of emotion on faces in frontotemporal dementia and Alzheimer's disease: a longitudinal study. Dement Geriatr Cogn Disord 2005;19(1):37-41. http://dx.doi.org/10.1159/000080969 